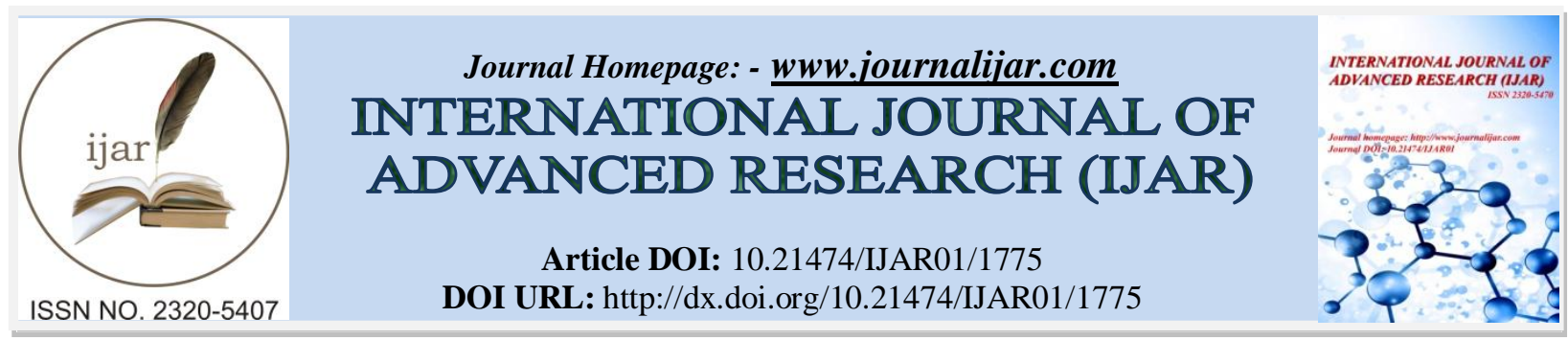

RESEARCH ARTICLE

\title{
THEMICRORNA-146BOVEREXPRESSION HELPS TO DIFFERENTIATE BENIGN NODULES FROM PAPILLARY THYROID CARCINOMA.
}

\author{
Shoroq Mohammed AL-Temimi (PhD $)^{1 *}$ and Adel Mosa AL-Rekabi (FICMS) ${ }^{2} *$. \\ 1. Department of Pathology, College of Medicine, Qaddissia University. \\ 2. Department of Surgery, College of Medicine, Qaddissia University.
}

\section{Manuscript Info}

Manuscript History

Received: 12 August 2016

Final Accepted: 22 September 2016

Published: October 2016

Key words:-

Solitary thyroid nodule, fresh tissues, miR-146b,RT-PCR

\section{Abstract}

Background: - MicroRNA-146b is one of the widely studied microRNAs in thyroid cancers and has been shown to be frequently upregulated in papillary thyroid carcinoma and plays a crucial role in tumorigenesis, progression and may become a potential therapeutic target and biomarker of tumor diagnosis and prognosis.

Aim of the study:- Estimation of microRNA-146b gene expression levels in fresh tissues of solitary thyroid nodulein comparison to normal adjacent tissue of same patients by using stem-loop follow by Taq-Man Real Time PCR (RT-PCR) technique to distinguish the benign nodule from papillary carcinoma and correlate with age , genderof patients, size of tumor, lymph node involvement and stage of tumors.

Material and methods:- Stem-loop Real time -PCR was performed to identify the level of microRNA-146b gene expression in fresh tissues of solitary thyroid nodule in comparison to normal adjacent tissues of same patients . The expression levels of microRNA-146b were normalized to housekeeping gene by using the livak method .

Results:-The expression level of tissue microRNA-146b in papillary thyroid carcinoma cases was significantly higher than that benign cases and normal adjacent tissues. Receiver operating characteristic curve analyses indicated that use of tissue microRNA-146b have a high diagnostic sensitivity and specificity for papillary thyroid carcinomain correlated with nodal status and advance tumor- stage.

Conclusion:-The microRNA-146b as a new novel diagnostic and prognostic biomarker forpapillary thyroid carcinoma.

Copy Right, IJAR, 2016,. All rights reserved.

\section{Introduction:-}

Thyroid cancer, which usually presents as a nodule,accounts for approximately $1 \%$ of all newly diagnosedcancer cases and its incidence is increasing faster thanany other cancer types, thus representing one of themost common and clinically worrying malignant tumorsof the endocrine system. Papillary thyroid carcinoma(PTC)represents the most frequent typology of thyroidmalignancy, with a prevalence of about $90 \%$ of alldiagnosed cases ${ }^{(1)}$. Fine-needle aspiration (FNA) biopsyand subsequent cytological analysis represents the mostreliable procedure to date to diagnose thyroid nodules ${ }^{(2)}$. FNA is highly specific for thyroid cancer; however, it has low sensitivity. In fact, $10 \%-$ 
$40 \%$ of the analyzednodules are detected as indeterminate lesions, thus creatingdifficulties for the optimal management of thesepatients ${ }^{(3)}$. Moreover, only $10 \%-30 \%$ of indeterminatethyroid nodules that are surgically resected are confirmedto be malignant ${ }^{(4)}$. As result, most diagnostic surgeriesare performed for benign thyroid nodules(BN). Conversely,patients who have undergone a surgical lobectomy andare found to have a tumor larger than $1 \mathrm{~cm}$, may require asecond surgery to remove the remaining thyroid lobe, thereby creating an important gap in the clinicaldecision pathway for thyroid nodules. Clearly, additionaldiagnostic markers are needed to guide the managementof patients with indeterminate thyroid nodules. In the pastfew years, significant progress has been made in developingmolecular markers for clinical use in FNA specimens,such as gene mutation panels and gene expression classifiers ${ }^{(5)}$. BRAF and KITmutation are the bestknown and studied prognostic markers for the diagnosisof PTC. The genetic characterization of BRAF and KIT status leadsto an increase of preoperative diagnostic accuracy up to $20 \%-30 \%{ }^{(6,7)}$,but still left a percentage of indeterminate samples. This due to the small number of screened patients and some malignant tumors do nothave the BRAF and KIT mutation, confirming the necessityof finding other molecular markers able to providea more accurate diagnosis ${ }^{(7)}$.

Recently, new prognostic markers are currently being explored for the effective diagnosis and treatment of PTC, and research into the potential for microRNAs(miRs) use in this area is currently a popular research topic ${ }^{(8,9)}$.

miRs are non-coding RNA molecules involved in the regulation of gene expression ${ }^{(10)}$. MiRs bind to messenger RNA (mRNA) and promote their degradation or prevent their translation into proteins. As miRs have been reported to be deregulatedin thyroid cancer ${ }^{(11)}$, and they have been shown tofunction both as tumor suppressors and oncogenes ${ }^{(12)}$, we decided to assess the prediction value of two miRstargeting the KIT gene; namely, miR-146b and miR-222.

MiR-146 is one of the widely studied miRs in thyroid cancers and has been shown to be frequently upregulated in $\mathrm{PC}^{(8,13)}$, anaplastic thyroid cancer ${ }^{(14)}$ and follicular thyroid cancer ${ }^{(9)}$. The miR-146 family includes two members: miR-146b and miR-146a .The miR-146b located on chromosome 10q24.32 ${ }^{(8)}$.

\section{Materials and methods:-}

\section{Selected cases:-}

The study was conducted during the period from March 2013 to January 2016 . This is a prospective study, where by 70 patients with newly diagnosed solitary thyroid nodule , were recruited at the Surgical Department/ALDiawania Teaching Hospital in Diawania City . Ultrasound-guided FNA cytology was performed as a part of the standard diagnostic protocol for patients with solitary thyroid nodule in Pathological Department/AL-Diawania Teaching Hospital in Diawania City .

After excision of the thyroid nodule samples ,takensevently-pairs of fresh tissues from thyroid nodule and normal adjacent tissues(NATs) ofsame cases which consider as internal control and preserved in Diethylpyrocarbonate(DEPC) water for total RNA extraction and for RT-PCR . Another 70 pairs specimens of both thyroid nodule and NATs for histopathological examination. The histopathological classification was performed according to the World Health Organization (WHO) classification tumor staging was carried out according to American Joint Committee Cancer(AJCC) ${ }^{(15)}$.

\section{MiRNA isolation from tissue:-}

RNA was extracted from tissues using the Trizol reagent (Bioneer ,Korea) according to the manufactures instructions. .RNA quality was assessed with a NanoDrop 1000 spectrophotometer. Total RNA samples of tissues were transferred to a $-20{ }^{\circ} \mathrm{C}$ freezer for preservation. The quality of RNA samples was analyzed by Nano-Drop 1000.

\section{Real-time RT-PCR for miR-146b quantification:-}

The miR-146b was analyzed using the TaqManmiR RT kit protocol (Applied Biosystems, Foster City, CA, USA) consisting in a first step of RT with an miR-specific primer (used miR-base ,as a database to design the primers) ${ }^{(16)}$ and in a second step the real-time PCR with TaqMan probes. Reverse transcriptase reactions were carried out to produce cDNAs in a volume of $15 \mathrm{ml}$ using $10 \mathrm{ng}$ total RNA for each sample, $50 \mathrm{nM}$ stem-loop RT primer, 1! RT buffer, $1 \mathrm{mM}$ each of dNTPs, $3.33 \mathrm{U} / \mathrm{ml}$ Multi- Scribe reverse transcriptase, and $0.25 \mathrm{U} / \mathrm{ml}$ RNase inhibitor. After incubation on ice for $5 \mathrm{~min}$, reactions were subjected to the following program of heating: $30 \mathrm{~min}$ at $168 \mathrm{C}, 30 \mathrm{~min}$ at $428 \mathrm{C}, 5 \mathrm{~min}$ at $858 \mathrm{C}$, and hold at $48 \mathrm{C}$. Real-time PCR was performed in triplicate in a 96-well optical plate on 
the Applied Biosystems 7700 Sequence Detection System. The volume of $20 \mathrm{ml}$ of each sample included 1! TaqMan Universal PCR Master Mix, 1 mlspecific miRNA Assay Mix (Applied Biosystems), and $1.34 \mathrm{ml}$ RT product. The reactions were incubated at $508 \mathrm{C}$ for $2 \mathrm{~min}$ and $958 \mathrm{C}$ for $10 \mathrm{~min}$, followed by 40 cycles of $958 \mathrm{C}$ for $15 \mathrm{~s}$ and $608 \mathrm{C}$ for $1 \mathrm{~min}$. All miR-146b quantification data were normalized to housekeeping gene like Glycer aldehyde 3-phosphate dehydrogenase (GAPDH) . The mRNA of GAPDH gene primers and probe were designed by using NCBI- Gene Bank data base and Primer 3 plus design online. The cDNAs primer of GAPDH as design as Random Hexamer primer and the primer used in qPCR was: forward, CAGCCGCATCT-TCTTTTGC and reverse, TTAAAAGCAGCCCTGGTGAC .Taq-Man probe for mGAPDH was: FAM-CCAGCCGAGCCACATCGCTCTAMRA. The data results of RT-qPCR for miR-146b and GAPDH were analyzed by the relative quantification gene expression levels (fold change) were based on the Ct values by using the Livak method (Fold change $=2-\Delta \Delta \mathrm{CT}$ ) that described by (Livak and Schmittgen $)^{(17)}$.

\section{Statistical analysis:-}

SPSS version 16 and Microsoft Office Excel 2007 were using in analysis of these data ,Chi-square test and Fisher exact test were used to study association between any two nominal variables. P-value of less than or equal to 0.05 was considered significant.

\section{Results:-}

\section{Clinicopathological characteristics of patients:-}

Table (1), shown a total of $(\mathrm{n}=70)$ solitary thyroid nodules patients, thirty cases $(42.86 \%)$ with PTC, other 40(57.14\%) cases with $\mathrm{BN}$, number and percentage of patients according to age ,gender ,lymph node (L.N) involvement and stage of tumor .

Table 1:- Clinicopathological characteristics of patients.

\begin{tabular}{|l|l|l|l|l|l|}
\hline \multicolumn{2}{|l|}{ PC $(\mathbf{n}=\mathbf{3 0})$} & BN $(\mathbf{n}=\mathbf{4 0})$ & \multicolumn{2}{l}{} \\
\hline Characteristic & N & \% & N & \% \\
\hline Age & $<45$ years & 14 & 46.66 & 10 & 25.64 \\
\hline & $\geq 45$ years & 16 & 51.61 & 30 & 75 \\
\hline Gender & Male & 10 & 32.26 & 23 & 58.97 \\
\hline & Female & 20 & 66.66 & 17 & 42.5 \\
\hline LN & Positive & 10 & 32.26 & --- & --- \\
\hline & Negative & 20 & 66.66 & --- & --- \\
\hline Stage & I & 17 & 56.66 & --- & -- \\
\hline & II & 8 & 25.81 & --- & --- \\
\hline & III & 5 & 16.13 & --- & - \\
\hline
\end{tabular}

Comparison the tissue microRNA-146b gene expression of papillary carcinoma, benign nodular thyroid and normal adjacent tissues .

Mean cancer tissue of miR-146b was statistical significantly higher than that NATs , 26.18 \pm 14.67 versus , 1 respectively $(\mathrm{P}<0.001)$. The amplification plots of tissue miR-146b in PTC showed in figure (1) .

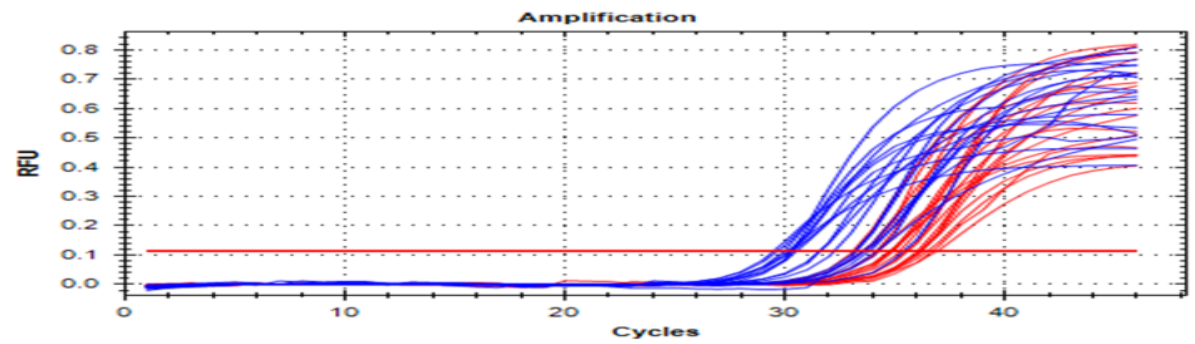

Figure 1:- Stem- Loop qRT-PCR amplification plots for miR-156b cDNA papillary cancer tissue patients by using Taq-Man probe . (FAM), where (blue amplification plot as papillary cancer tissue samples) and (red amplification plot as normal adjacent tissue samples). 
Mean BN thyroid tissues of miR-146b was statistical significantly higher than that NATs , 4.05 \pm 0.23 versus 1 , respectively $(\mathrm{P}<0.001)$. The amplification plots of tissue miR-146b in BN showed in figure (2) .

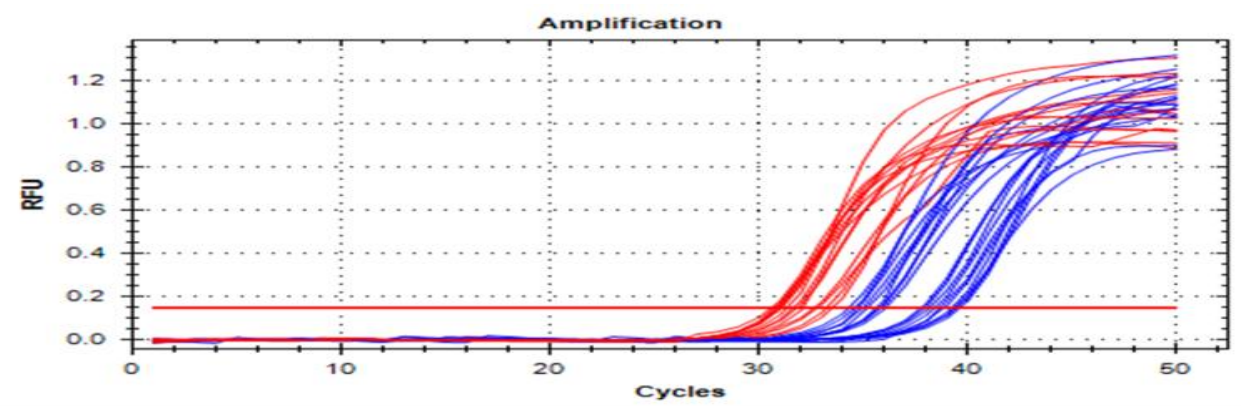

Figure 2:- Stem- Loop RT-PCR amplification plots for microRNA-146b cDNA in patients with benign nodular thyroid by using Taq-Man probe .where (blue amplification plot as benign nodular thyroid tissue samples) and (Red amplification plot as normal adjacent tissue samples).

Mean cancer tissue of miR-146b was statistical significantly higher from BN thyroid tissues, $26.18 \pm 14.67$ versus $4.05 \pm 0.23$, respectively $(\mathrm{P}<0.001)$.

Correlation of microRNA and clinicopathological features of PTC and BN:Association between tissue level of microRNA-146b and sex of patients:-

The result of present study showed that there was no statistical significance correlation between tissue level of miR$146 \mathrm{~b}$ of PTC and BN with sex of patients (P>0.005), as shown in table (2).

Correlation between tissue microRNA-146b gene expressions with age:-

The result of present study showed that there was no statistical significance correlation between tissue level of miR$146 \mathrm{~b}$ of PTC and BN with age of patients (P>0.005), as shown in table(2), figure (3) .

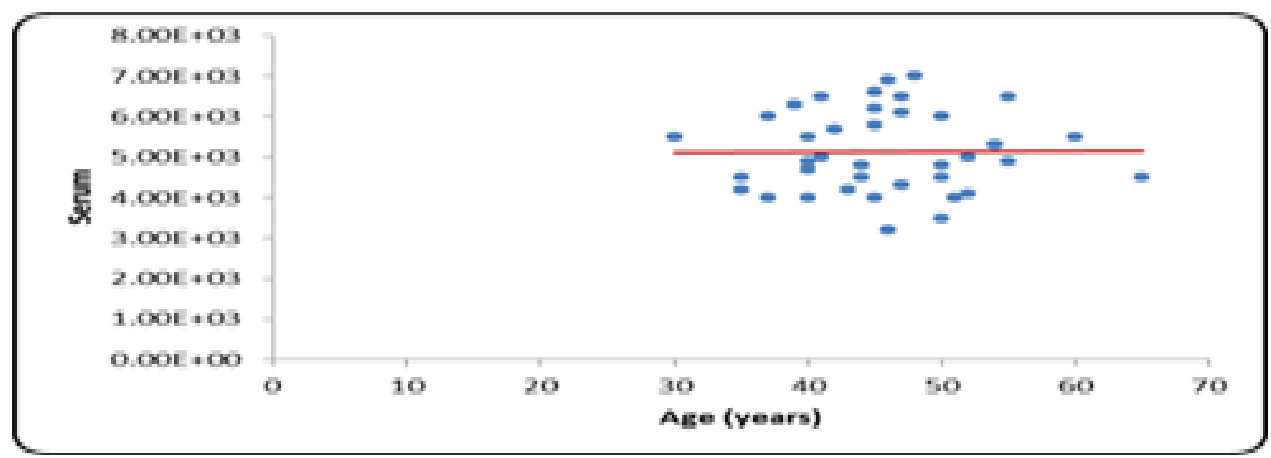

Figure 3:- Spearman correlation between age of patients and tissue of microRNA-146b.

Even when divided in two group $(<45$ and $\geq 45)$, no statistical significant between mean fold change of miR-146b tissue levels of PTC and BN with age of patients ( $p>0.05)$. As shown in table (2).

Association between tissue level of microRNA-146b and size of thyroid nodules:-

When divided in two group $(\leq 2$ and $>2)$, no statistical significant between mean fold change of miR-146b tissue levels of PTC and BN with size of tumors ( $>>0.05)$, as shown in table (2).

\section{Association between tissue level of microRNA-146b and L.N involvement:-}

The mean tissue miR-146b fold change of PTC patients with positive L.N was statistical significantly higher from that of patients with negative L.N involvement, $(40.43 \pm 6.92)$ versus $(20.02 \pm 5.12)$, respectively $(\mathrm{P}<0.001)$, as shown in table (2). 


\section{Association between tissue level of microRNA-146b and stage of tumor:-}

The mean fold change of tissue miR-146b in PTC patients with higher stage (III) was statistical significantly higher than that early stage (I,II), $(40.4 \pm 19.66)$ versus , $(20.32 \pm 10.00),((\mathrm{P}<0.05)$, as shown in table $(2)$.

Table 2:- Clinicopathological features and their correlation with tissue levels of miR-146b

\begin{tabular}{|l|l|l|l|l|l|}
\hline Papillary carcinoma & $\mathrm{N}$ & $\%$ & Mean tissuemiR & SD & P-value \\
\hline \hline Gender & & & & & \\
\hline Male & 10 & 32.26 & 27.81 & 13.67 & 0.422 \\
\hline Female & 20 & 66.66 & 25.50 & 10.43 & \\
\hline Age & & & & & \\
\hline$<45$ years & 14 & 46.66 & 25.99 & 10.25 & 0.718 \\
\hline$\geq 45$ years & 16 & 51.61 & 27.11 & 11.47 & \\
\hline Size & & & & & \\
\hline$\leq 2 \mathrm{~cm}$ & 20 & 66.66 & 25.70 & 11.20 & 0.397 \\
\hline$>2 \mathrm{~cm}$ & 10 & 32.26 & 27.19 & 12.42 & \\
\hline LN & & & & & \\
\hline Positive & 10 & 32.26 & 40.43 & 6.92 & $<0.001^{*}$ \\
\hline Negative & 20 & 66.66 & 20.02 & 5.12 & \\
\hline Stage & & & & & \\
\hline I,II & 25 & 83.33 & 20.32 & 10.00 & $0.001^{*}$ \\
\hline III & 5 & 16.13 & 40.46 & 19.66 & \\
\hline Benign nodule & & & & & \\
\hline Gender & 23 & 58.97 & 4.5 & 0.20 & 0.702 \\
\hline Male & 17 & 42.5 & 4.2 & 0.46 & \\
\hline Female & & & & & \\
\hline Age & & & & & \\
\hline$<45$ years & 10 & 25.64 & 4.4 & 0.19 & 0.265 \\
\hline$\geq 45$ years & 30 & 75 & 4.5 & 0.31 & \\
\hline Size & & & & 0.41 & 0.374 \\
\hline$\leq 2 \mathrm{~cm}$ & 7 & 17.95 & 4 & 0.33 & \\
\hline$>2 \mathrm{~cm}$ & 33 & 82.5 & 4.5 & & \\
\hline
\end{tabular}

predictive value of tissue microRNA-146b in the patients:-

To evaluate the diagnostic value of tissue miR-146b for PTC and BN, by using the RT-qPCR technique , an Receiver Operator Characteristic (ROC) curve analysis was done:

The best cutoff value for tissue miR-146b in PTC was(14.55) with a specificity of $100 \%$, sensitivity of $90.30 \%$ and ) excellent accuracy(AUC, as shown in table (3) and figure (4) .

Table 3:- The cut of value of tissue microRNA-146b in the discrimination of patients with papillary thyroid carcinoma from benign nodular and healthy control groups

\begin{tabular}{|l|l|l|l|l|l|}
\hline Parameter & Cutoff value & Sensitivity & Specificity & Accuracy (AUC) & P-value \\
\hline PC serum mir & $\mathbf{1 4 . 5 5}$ & $\mathbf{9 0 . 3 0 \%}$ & $\mathbf{1 0 0 \%}$ & $\mathbf{9 8 . 2 \% ( 0 . 9 8 2 )}$ & $<\mathbf{0 . 0 0 1}$ \\
\hline
\end{tabular}




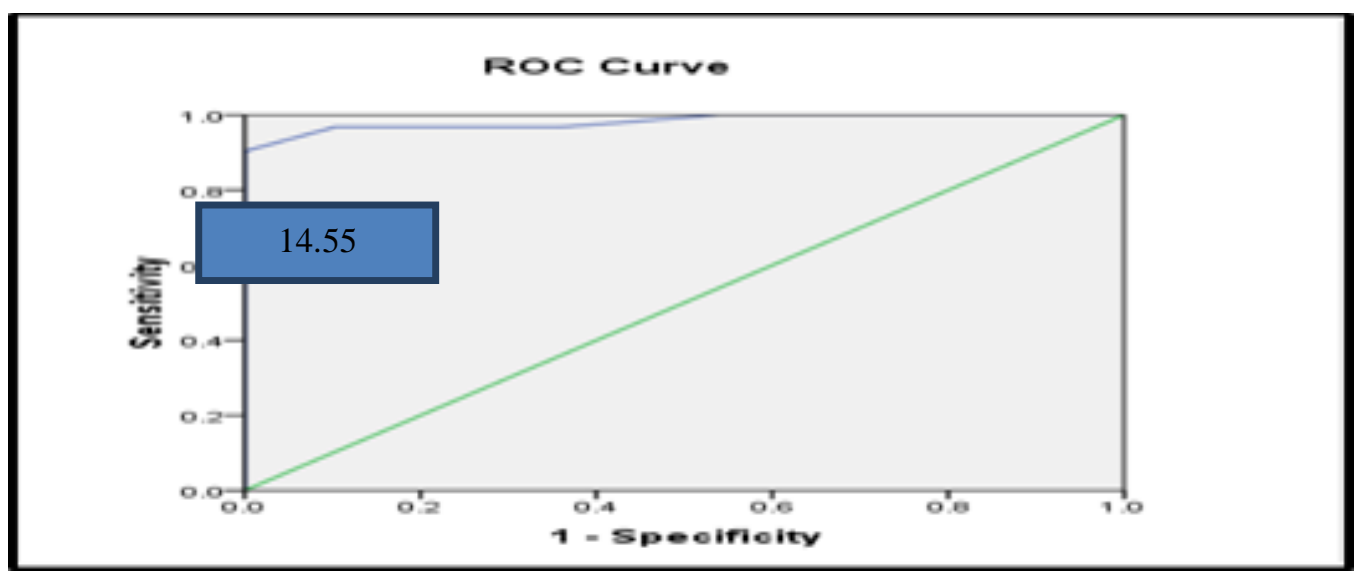

Figure 4:- ROCcure analyses of tissue microRNA-146b in the discrimination of patients with papillary thyroid carcinoma from benign nodular andnormal adjacent tissues .

And the best cutoff value for tissue miR-146b in BN groups was(3.12) with a specificity of $100 \%$, sensitivity of $96.80 \%$ and excellent AUC, as shown in table (4) and figure (5) .

Table 4:- The cut of value of oftissue microRNA-146b in the discrimination of patients with benign thyroid nodules from papillary thyroid carcinoma.

\begin{tabular}{|l|l|l|l|l|l|}
\hline Parameter & Cutoff value & Sensitivity & Specificity & Accuracy (AUC) & P-value \\
\hline BN serum mir & $\mathbf{3 . 1 2}$ & $\mathbf{9 6 . 8 0 \%}$ & $\mathbf{1 0 0 \%}$ & $\mathbf{9 8 . 2} \%(\mathbf{0 . 9 8 2})$ & $<0.001$ \\
\hline
\end{tabular}

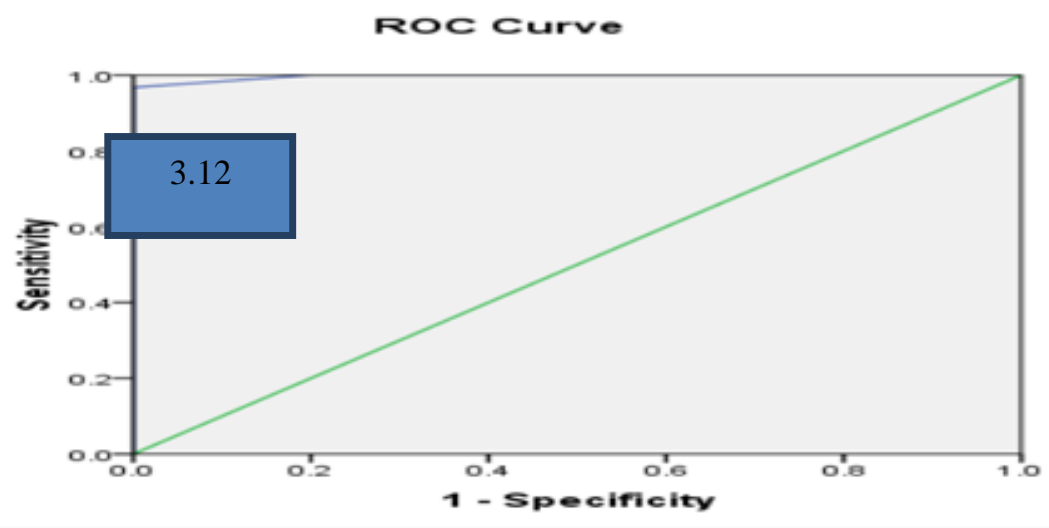

Figure 5:- ROCcure analyses of tissue microRNA-146b in the discrimination of patients with benign thyroid nodules from papillary thyroid carcinoma .

Validity of tissue microRNA-146b gene expression folds change as prognostic marker:-

To find the cutoff value of fold change for miR-146b gene expression, that predict PTC patient with positive lymph node metastasis and higher stage (III), an ROC curve analysis was performed.

It was found that miR-146b gene expression fold change can predict positive lymph node and higher stage (III ) . The ROC results demonstrated that the excellent AUC was (100\%),(98.5\%), when the cutoff value was set to the optimal point, $\geq 20.1, \geq 35.5$; specificity was $100 \%, 97.1 \%$; sensitivity was $100 \%, 100 \%$ respectively. As shown in figure (6) . 


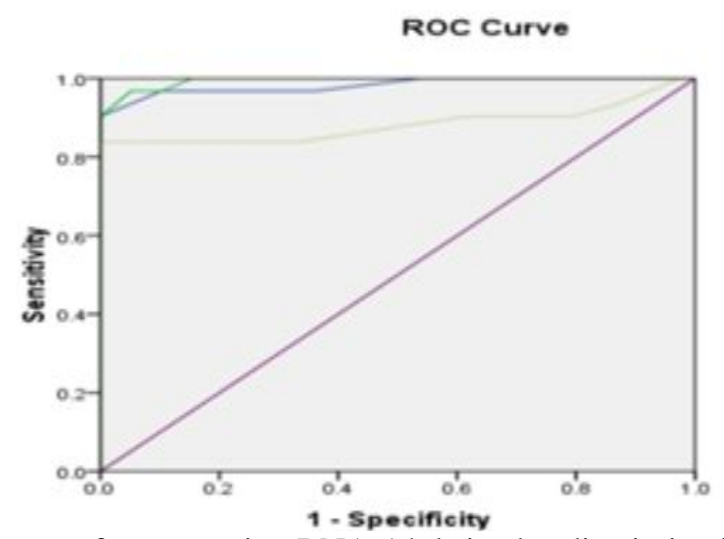

Figure 6:- ROCcure analyses of serum microRNA-146b in the discrimination of patients with papillary thyroid carcinoma and lymph node involvement and higher stage . Where blue line for patients with papillary thyroid carcinoma. Yellow line for patientsthat predicts higher stage .Green line for patients that predicts positive L.N .

\section{Discussion:-}

The primary goal of the evaluation of patients withnodular thyroid disease is the exclusion of thyroidmalignancy, altrerationof gene expression for target gene therapy and for follow up patients and management .At present, miR have become the rising stars in cancer genetics. MiRs are excellent candidates for novel molecular targeting treatments because of their ability to regulate multiple genes in molecular pathways. Chemotherapy is an important component in the treatment paradigm for cancers. However, the resistance of cancer cells to chemotherapeutic agents frequently results in the subsequent recurrence and metastasis. Recently, a new data suggest that the expression level of miR-146b in tumor tissue and plasma might be used as a biomarker to predict adjuvant platinumbased chemotherapy response and disease free survival in patients with non-small-cell lung cancer. Thus, it may serve as a novel therapeutic target to modulate platinum-based chemotherapy ${ }^{(9)}$.

In the present study, a tissue samples for miR expression level by RT-PCR validation in patients with PTC , BN and in NATs. We identified the miR-146b in PTC was significant higher than that BNs and NATs. We speculated that tissuemiR-146b may originate from tumor cells or a product of tumor cell death and lysis. The results of present study were in concordance with other studies ${ }^{(9,18-24)}$.

Both neck U/S and CT have limited value for the prediction of L.N involvement; hence it is crucial to find novel biomarkers that can be used for this purpose and also as a standard for optimizing therapy and long-term follow-up care.

The results of present study demonstrated that the expression levelof tissue miR-146b in PTC with positive L.N and higher stage III was statistical significant higher than that patients with negative L.N and early stage of cancer ,suggesting its role in metastasis and functional analyses of miR-146b revealed its involvement in migration, invasion, proliferation and cell cycle ${ }^{(9)}$. The results of present study were in concordance with other studies ${ }^{(9,18-23)}$ .On the other hand, another study performed in (91)cases of PTC patients failed to find any significant association of miR-146b with L.N involvement ${ }^{(24)}$. The reason for this remains unclear and it might be contributed by the use of a different platform and/or chemistry for detection and also possibly the intrinsic variability in the cohort of patients. In addition, even though the tissues used in the studies were verified by a pathologist, the authors did not mention about the percentage of cancer cells. Perhaps a more refined quality control and assessment of the tumor specimens before being subjected to expression profiling will be able to explain such contradictory findings.

In the results of the present study, no statistical significant difference in PTC and BN in comparison to age ,sex of patients and nodular size. These results were in concordance with other study ${ }^{(9,18-24)}$.

Best for the present knowledge, this study could be the first study of its type to be conducted in Iraq, evaluating tissue miR-146b gene expression by RT-qPCR, in the same series fresh tissue of thyroid nodule /apparently NAT samples in a sample of Iraqi patients. There was no baseline study regarding miR-146b gene expression stratification in apparently NATs in Iraqi individuals. Although, similar studies were conducted abroad to stratify miR-146b in other countries such as ${ }^{(9,18-24)}$. 


\section{Conclusion:-}

The extraction of RNA and identification of miR-146b from the fresh tissue of individuals diagnosed with thyroid nodule is feasible and RT- PCR is a novel and practical means for investigation of tissue miR samples.MiR-146b could be a useful biomarker for detection of PTC, detect of higher stage and positive L.N involvement .However, studies with larger number of patients are needed to validate the present study and to investigate whether other miRs are also capable of indicating PTCdetection and progression and more importantly whether miR-146b is the best choice among potential PTC biomarkers .

\section{References:-}

1. Nikiforova MN, Nikiforov YE. Molecular genetics of thyroid cancer:implications for diagnosis, treatment and prognosis. Expert Rev MolDiagn.2008;8:83-95.

2. Gharib H, Papini E, Paschke R, et al. European Thyroid Association medical guidelines for clinical practice forthe diagnosis and management of thyroid nodules. J Endocrinol Invest. 2010;33:51-6.

3. Nikiforov YE, Steward DL, Robinson-Smith TM, et al. Molecular testing for mutations in improving the fineneedle aspirationdiagnosis of thyroid nodules. J ClinEndocrinolMetab. 2009;94:2092-8.

4. Baloch ZW, Fleisher S, LiVolsi VA, et al. Diagnosis of "follicularneoplasm": a gray zone in thyroid fine-needle aspiration cytology. DiagnCytopathol. 2002;26:41-4.

5. Hsiao SJ, Nikiforov YE. Molecular approaches to thyroid cancer diagnosis.EndocrRelat Cancer. 2014;21:T301313.

6. Marchetti I, Iervasi G, Mazzanti CM, et al.Detection of the BRAF(V600E) mutation in fine needle aspiration cytology ofthyroid papillary microcarcinoma cells selected by manual macrodissection:an easy tool to improve the preoperative diagnosis. Thyroid. 2012;22:292-8.

7. Tomei S, Mazzanti C, Marchetti I, et al. c-KITreceptor expression is strictly associated with the biological behaviour ofthyroid nodules. J Transl Med. 2012;10:7.

8. Wojtas B, Ferraz C, Stokowy T, et al. Differential miRNA expression defines migration and reduced apoptosis in follicular thyroid carcinomas. Mol Cell Endocrinol. 2014, 388: 1-9.

9. Chou CK, Yang KD, Chou FF, et al. Prognostic implications of miR-146b expression and its functional role in papillary thyroid carcinoma. J ClinEndocrinolMetab. 2013,98: 196-205.

10. He L, Hannon GJ. MicroRNAs: Small RNAs with big roles in gene regulation. Nat Rev Genet . 2004;5:522-31.

11. Marini F, Luzi E, Brandi ML. MicroRNA Role in Thyroid Cancer Development.J Thyroid Res. 2011;407-4123.

12. Wiemer EA. The role of microRNAs in cancer: no small matter. Eur J Cancer.2007;43:1529-44.

13. Sun Y, Yu S, Liu Y, et al. Expression of miRNAs in papillary thyroid carcinomas is associated with BRAF mutation and clinicopathological features in Chinese patients. Int J Endocrinol. 2013; 12:87-95.

14. Fassina A, Cappellesso R, Simonato F, et al. A 4-MicroRNA signature can discriminate primary lymphomas from anaplastic carcinomas in thyroid cytology smears.CancerCytopathol .2014;122: 274-81.

15. Edge S, Compton C. The American Joint Committee on Cancer: The 7th Edition of theAJCC cancer staging manual and the future of TNM. Ann. Surg. Oncol. 2010; 17:1471-1474.

16. miRBase: The microRNA Database. Available online: http://www.mirbase.org/ 2014.

17. Livak and Schmittgen . The 2- $\Delta \Delta \mathrm{CT}$ (Livak) Method Real-Time PCR. Applications Guide .2001: 41.

18. Keutgen XM, Filicori F, Crowley MJ, et al. A panel of four miRNAs accurately differentiates malignant from benign indeterminate thyroid lesions on fine needle aspiration. Clin Cancer Res .2012;18:2032-8.

19. Federica Panebianco, Chiara Mazzanti , Sara Tomei, et al .The combination of four molecular markers improves thyroid cancer cytologic diagnosis and patient management. BMC Cancer .2015; 15:918.

20. Yang Z, Yuan Z, Fan Y, et al . Integrated analyses of microRNA and mRNA expression profiles in aggressive papillary thyroid carcinoma . Mol Med Rep . 2013 8; 1353-8.

21. Deng $\mathrm{X}, \mathrm{Wu} \mathrm{B}, \mathrm{Xiao} \mathrm{K}$, et al . MiR-146b-5p promotes metastasis and induces epithelial-mesenchymal transition in thyroid cancer by targeting ZNRF3. Cell PhysiolBiochem. $2015 ; 35: 71-82$.

22. Acibucu F, Dokmetas HS, Tutar Y, et al. Correlations between the expression levels of micro-RNA146b, 221, 222 and p27Kip1 protein mRNA and the clinicopathologic parameters in papillary thyroid cancers. ExpClinEndocrinol Diabetes .2014 ;122: 137-43.

23. James C, Lee A. Justin S, et al. MicroRNA Expression Profiles in the Management of Papillary Thyroid Cancer. The Oncologist . 2014;19:1141-1147

24. Wang Z, Zhang H, He L, et al. Association between the expression of four upregulatedmiRNAs and extrathyroidal invasion in papillary thyroid carcinoma. Onco Targets Ther.2013;6:281-7. 